\title{
Deep divergences and extensive phylogeographic structure in a clade of lowland tropical salamanders
}

Sean M Rovito ${ }^{1,2}$, Gabriela Parra-Olea ${ }^{2 *}$, Carlos R Vásquez-Almazán ${ }^{3}$, Roberto Luna-Reyes ${ }^{4}$ and David B Wake ${ }^{5}$

\begin{abstract}
Background: The complex geological history of Mesoamerica provides the opportunity to study the impact of multiple biogeographic barriers on population differentiation. We examine phylogeographic patterns in a clade of lowland salamanders (Bolitoglossa subgenus Nanotriton) using two mitochondrial genes and one nuclear gene. We use several phylogeographic analyses to infer the history of this clade and test hypotheses regarding the geographic origin of species and location of genetic breaks within species. We compare our results to those for other taxa to determine if historical events impacted different species in a similar manner.

Results: Deep genetic divergence between species indicates that they are relatively old, and two of the three widespread species show strong phylogeographic structure. Comparison of mtDNA and nuclear gene trees shows no evidence of hybridization or introgression between species. Isolated populations of Bolitoglossa rufescens from Los Tuxtlas region constitute a separate lineage based on molecular data and morphology, and divergence between Los Tuxtlas and other areas appears to predate the arrival of $B$. rufescens in other areas west of the Isthmus of Tehuantepec. The Isthmus appears responsible for Pliocene vicariance within B. rufescens, as has been shown for other taxa. The Motagua-Polochic fault system does not appear to have caused population vicariance, unlike in other systems.

Conclusions: Species of Nanotriton have responded to some major geological events in the same manner as other taxa, particularly in the case of the Isthmus of Tehuantepec. The deep divergence of the Los Tuxtlas populations of B. rufescens from other populations highlights the contribution of this volcanic system to patterns of regional endemism, and morphological differences observed in the Los Tuxtlas populations suggests that they may represent an undescribed species of Bolitoglossa. The absence of phylogeographic structure in B. nympha, in contrast to the other widespread species in the subgenus, may be due to historical forest contraction and more recent range expansion in the region. Phylogeographic data provide substantial insight into the evolutionary history of these morphologically similar species of salamanders, and contribute to our understanding of factors that have generated the high biodiversity of Mesoamerica.
\end{abstract}

Keywords: Salamander, Phylogeography, Mesoamerica, Isthmus of Tehuantepec, Biogeography, Bolitoglossa

\footnotetext{
* Correspondence: gparra@ibiologia.unam.mx

${ }^{2}$ Instituto de Biología, Universidad Nacional Autónoma de México, AP 70-153,

Circuito Exterior, Ciudad Universitaria, CP 04310, México, D.F., México

Full list of author information is available at the end of the article
} 


\section{Background}

Phylogeography and molecular systematics have been of great utility for delimiting the species boundaries of morphologically cryptic taxa [1-3] and understanding the origins of diversity both at and below the species level [4-7]. Within taxa, high genetic diversity in a small region often indicates long-term historical persistence in the face of environmental change, while genetic breaks between populations suggest a more complex demographic history involving periods of isolation or restricted gene flow. Climatic barriers or geological features are often associated with such phylogeographic breaks and can be hypothesized to have caused population isolation. Given that allopatric divergence is hypothesized to be the prevailing geographic mode of speciation for most animal taxa [8], understanding which barriers have led to divergence within species should elucidate the impact of such barriers on species diversity over longer timescales. An improved understanding of both species boundaries and phylogeographic structure enables tests of hypotheses related to the geographic origin of clades, connecting their divergence to regional processes, and facilitates comparisons of patterns of lineage divergence across taxa.

Understanding the historical factors promoting population divergence and species formation is of particular interest in areas of high species diversity, such as humid tropical regions. Here we investigate how the complex geological history of southern Mexico and Nuclear Central America, the area between the Isthmus of Tehuantepec and the Nicaraguan Depression [9], relates to population divergence in a group of morphologically similar plethodontid salamanders. We interpret their divergence history in the light of patterns seen in other taxa in order to understand how regional biogeography may have influenced current patterns of species diversity and faunistic relationships between subregions.

Salamanders have often been shown to have historical signatures of geological or climatic changes in their geographic patterns of genetic variation [10-12], due to their short dispersal distances [13] and environmental sensitivity [14]. Most species of Neotropical salamanders, however, are characterized by small range sizes, and often are known from only a single mountain range [15-17], precluding studies of population differentiation at a regional scale. This tendency toward small range size could be a direct result of stronger population isolation in the tropics, leading to higher rates of allopatric speciation and thus producing many species with small geographic ranges $[18,19]$. The few wideranging tropical salamanders offer the chance to study species of low dispersal ability that are distributed across major geographic barriers, and allow us to understand the processes that may have been important in generating the high diversity seen in the tropical salamanders as a whole.

Our study focuses on species of Bolitoglossa subgenus Nanotriton, which has only four described species, yet is distributed throughout a wide area of Mesoamerica [20]. The species of this subgenus span multiple biogeographic boundaries in Mesoamerica, including the Isthmus of Tehuantepec, which appears to have restricted dispersal of mesic-adapted species [21-23], while acting as a corridor for arid-adapted species [24]. Species in the subgenus occur in multiple geological regions, including the eastern terminus of the Trans-Mexican Volcanic Belt (TMVB) and Los Tuxtlas region in Veracruz, the Northern highlands of Oaxaca, the Sierra de los Chimalapas, Mexico and on both the Pacific and Caribbean sides of Chiapas, Mexico and Guatemala in Nuclear Central America (Figure 1). Bolitoglossa rufescens, the most widely distributed species in the subgenus, ranges across the Isthmus of Tehuantepec, making it one of only three salamander species to occur on both sides of this major barrier $[25,26]$. As presently known, $B$. rufescens also occurs on both sides of the Motagua-Polochic fault system, an important barrier for many other taxa in Central America [21,22].

Although species of Nanotriton generally occur only in mid- to low elevations, populations are known from up to $2000 \mathrm{~m}$ elevation and are not found in dry forest, savannah, or other low-elevation subhumid habitats. Many populations are currently associated with banana plantations and other anthropogenic habitats adjacent to forest, but salamanders can also be found in forested habitats. Because of these associations, species of Nanotriton, like higher elevation salamanders, could be used to test for effects of historical forest fragmentation or expansion, in addition to examining effects of geological barriers such as major mountain ranges or fault zones.

In at least two localities, two species of the subgenus are found in sympatry $[27,28]$ and another instance of near-sympatry is known [29], despite overall morphological similarity of these species that might be expected to limit their co-occurrence [27]. The only obvious character separating two of the species (Bolitoglossa chinanteca and $B$. occidentalis) from the other two (B. nympha and $B$. rufescens) is the presence or absence of maxillary teeth, and even this character is variable within B. rufescens [29]. This group of salamanders exhibits little variation in morphology, possibly because of their generally paedomorphic state; development of features such as digits or skull bones that distinguish other species of salamanders is truncated, leading to a reduction or absence of these elements [30,31]. Because of this high similarity in external appearance, genetic markers provide one of the best tools to delimit these species' geographical limits, an essential endeavor for understanding the biogeographic history of the group. The use of both mtDNA and nuclear markers also 

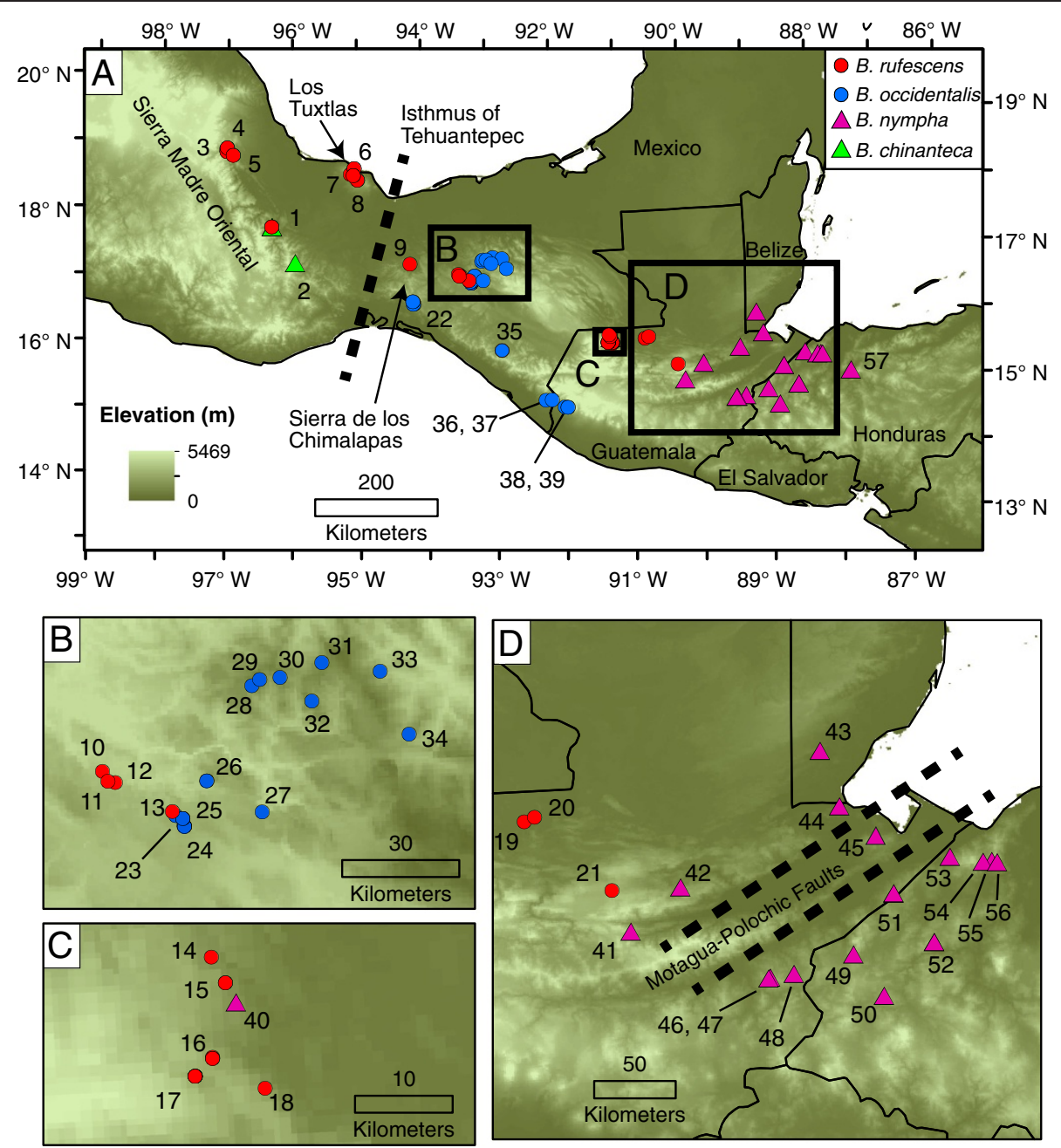

Figure 1 Samples used in phylogenetic analyses. Red circles: Bolitoglossa rufescens; blue circles: B. occidentalis; pink triangles: B. nympha; green triangles: B. chinanteca. Numbers correspond to localities listed in Table 1. Species assignment based on phylogenetic analyses (see Results).

allows us to test for a signature of introgression across species boundaries, with finer-scale sampling in possible areas of contact identified by analyses of allozymes [29].

In this study, we use both mitochondrial (mtDNA) and nuclear DNA (nDNA) to investigate phylogeographic structure within species of Nanotriton as well as phylogenetic relationships between described species. We compare patterns of mtDNA and nDNA to look for discordance that might indicate introgression across species boundaries, especially near previously identified possible contact zones, and to identify hybrids or signatures of past population admixture. We use a likelihood-based phylogeographic history estimation method (Phylomapper [32]) to test hypotheses of the geographic location of the origins of clades. In particular, we examine in which biogeographic region (southern Mexico vs. Central America) and in which mountain range or subregion species originated. We examine the impact of major biogeographic boundaries known from other taxa on the phylogeographic patterns within these salamander species, and compare patterns across these boundaries to those seen in other taxa.

\section{Results}

Phylogenetic analyses reveal deep divergences between species, as well as a high degree of phylogeographic structure within species. The mtDNA results (Figure 2) strongly support the monophyly of Nanotriton (likelihood bootstrap proportion $[\mathrm{BS}]=100$, posterior probability $[\mathrm{PP}]=1.0$ ), as well as that of all four members of the group: Bolitoglossa occidentalis $(\mathrm{BS}=99, \mathrm{PP}=1.0)$, B. chinanteca $(\mathrm{BS}=100, \mathrm{PP}=1.0), B$. nympha $(\mathrm{BS}=100$, $\mathrm{PP}=1.0)$ and $B$. rufescens $(\mathrm{BS}=100, \mathrm{PP}=1.0)$. B. occidentalis and $B$. chinanteca are strongly supported as sister taxa $(\mathrm{BS}=99, \mathrm{PP}=1.0)$, as are B. nympha and B. rufescens $(\mathrm{BS}=96, \mathrm{PP}=0.99)$. 


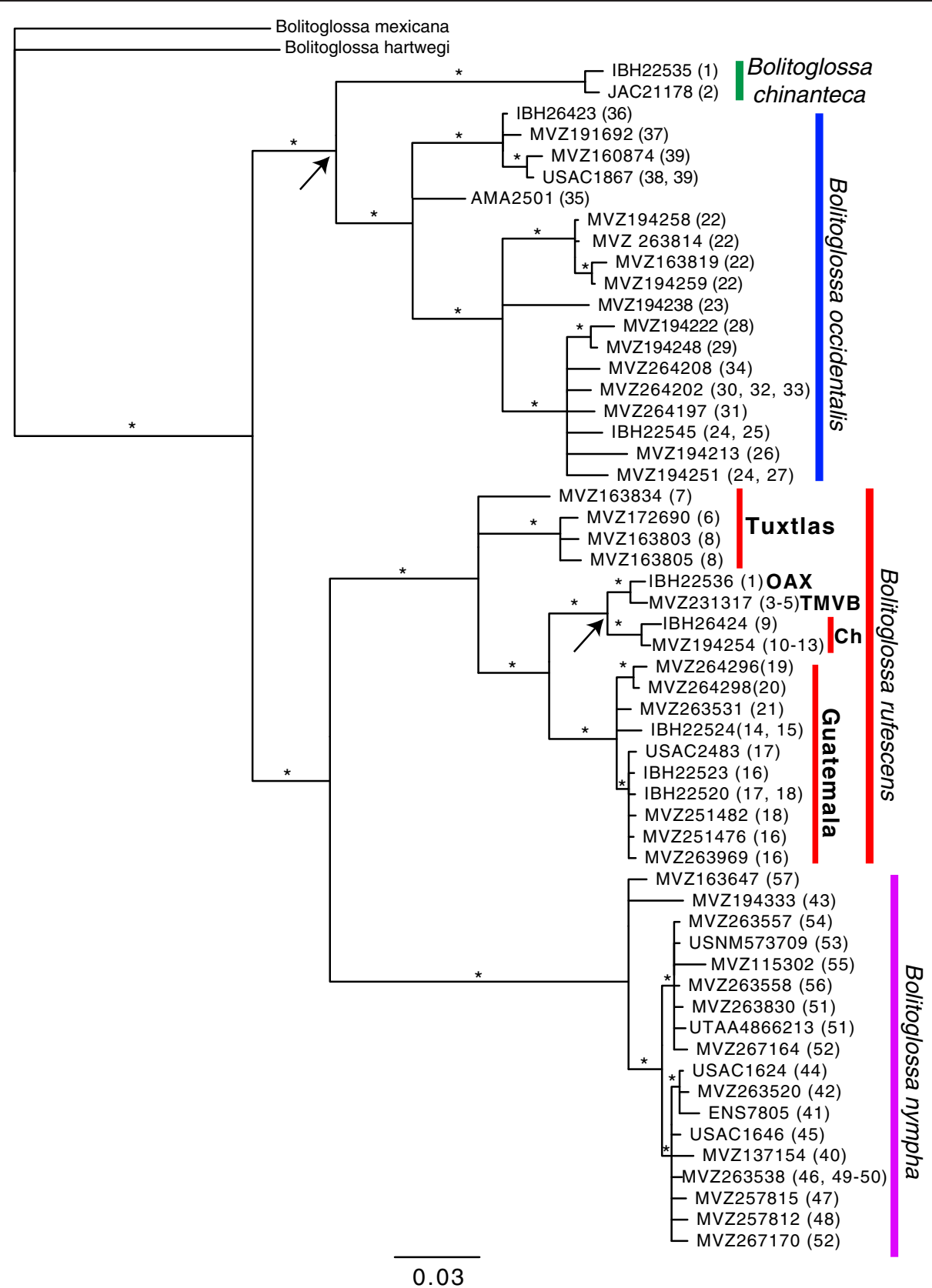

Figure 2 Mitochondrial gene tree from RAxML analysis of $16 \mathrm{~S}$ and cytb sequence data. Asterisks indicate branches with bootstrap proportions $>70$ for ML analysis and posterior propabilities $>95$ for Bayesian analysis. Numbers in parentheses after voucher numbers refer to all sampled localities (from Table 1) where haplotype was found. Geographic areas are shown for samples of Bolitoglossa rufescens. Abbreviations: Ch-Chiapas; TMVB-eastern terminus of Trans-Mexican Volcanic Belt; OAX-highlands of northern Oaxaca. Arrows indicate nodes whose daughter lineages are separated by the Isthmus of Tehuantepec.

Within species, markedly different patterns of phylogeographic structure emerge. Bolitoglossa chinanteca shows little divergence in $16 \mathrm{~S}$ sequence between the only known localities (GTR distance $=0.004$ substitutions/site). Bolitoglossa occidentalis shows several strongly supported lineages (BS $>70, \mathrm{PP}>95)$ corresponding to populations from 1) the Pacific coast of Chiapas and Guatemala,
2) a single population from the eastern side (Caribbeandraining) side of the Sierra Madre de Chiapas (Locality 35; Figure 1, Table 1), 3) a single population from Cerro Baúl in the isolated Sierra de los Chimalapas (Locality 22), and 4) various populations from other areas of northern and central Chiapas (Localities 23-34). Maximum GTR distances between samples of $B$. occidentalis are large $(0.043$ 
Table 1 Populations of Bolitoglossa (Nanotriton) used in phylogenetic analyses

\begin{tabular}{|c|c|c|c|}
\hline Locality number & Species & Country: State/Province & Locality \\
\hline 1 & B. chinanteca, B. rufescens & Mexico: Oaxaca & $9.2 \mathrm{~km}$ S of Valle Nacional on Hwy 175 \\
\hline 2 & B. chinanteca & Mexico: Oaxaca & Coconales-Zacatepec highway, Sierra Mixe \\
\hline 3 & B. rufescens & Mexico: Veracruz & Cerro Chicahuaxtla, Cuautlapan \\
\hline 4 & B. rufescens & Mexico: Veracruz & Fortín de las Flores \\
\hline 5 & B. rufescens & Mexico: Veracruz & Coetzala, 8.9 km S of Amatlán \\
\hline 6 & B. rufescens & Mexico: Veracruz & Playa Escondida, 30 km NNE Catemaco \\
\hline 7 & B. rufescens & Mexico: Veracruz & 9.2 km NE of Catemaco \\
\hline 8 & B. rufescens & Mexico: Veracruz & Lake Catemaco, 2.5 km SE Coyame \\
\hline 9 & B. rufescens & Mexico: Oaxaca & 1.5 km SE of La Fortaleza \\
\hline 10 & B. rufescens & Mexico: Chiapas & 10 km NW Ocuilapa, Ocozocautla \\
\hline 11 & B. rufescens & Mexico: Chiapas & 15 km N Ocozocuautla \\
\hline 12 & B. rufescens & Mexico: Chiapas & 26.5 km N Ocozocuautla \\
\hline 13 & B. rufescens & Mexico: Chiapas & 12.4 km W Berriozabal \\
\hline 14 & B. rufescens & Guatemala: Huehuetenango & Siglo Veinte Ermin, Barillas \\
\hline 15 & B. rufescens & Guatemala: Huehuetenango & Las Victorias Chancolin, Barillas \\
\hline 16 & B. rufescens & Guatemala: Huehuetenango & Palmiras de Chiblac, Barillas \\
\hline 17 & B. rufescens & Guatemala: Huehuetenango & El Valle, $4.5 \mathrm{~km} \mathrm{~N}$ of RN 9 at Aldea La Concepción \\
\hline 18 & B. rufescens & Guatemala: Huehuetenango & San Ramon, Barillas \\
\hline 19 & B. rufescens & Guatemala: Alta Verapaz & western border of Parque Nacional Laguna Lachua \\
\hline 20 & B. rufescens & Guatemala: Alta Verapaz & Parque Nacional Laguna Lachua \\
\hline 21 & B. rufescens & Guatemala: Alta Verapaz & Finca Cuxmax, San Pedro Carchá \\
\hline 22 & B. occidentalis & Mexico: Chiapas & Cerro Baúl \\
\hline 23 & B. occidentalis & Mexico: Chiapas & 11.4 km NW Berriozabal \\
\hline 24 & B. occidentalis & Mexico: Chiapas & Vista Hermosa, 7.5 km N Berriozabal \\
\hline 25 & B. occidentalis & Mexico: Chiapas & Cuhumbac, 10.4 km N Berriozabal \\
\hline 26 & B. occidentalis & Mexico: Chiapas & 11.2 km N San Fernando, Tuxtla Gutiérrez \\
\hline 27 & B. occidentalis & Mexico: Chiapas & W San Fernando, 13 km N Tuxtla Gutiérrez \\
\hline 28 & B. occidentalis & Mexico: Chiapas & 15.3 km ENE Copainala \\
\hline 29 & B. occidentalis & Mexico: Chiapas & 9 km ENE Coapilla \\
\hline 30 & B. occidentalis & Mexico: Chiapas & 2.7 km W Pantepec \\
\hline 31 & B. occidentalis & Mexico: Chiapas & Puerto del Viento, Pueblo Nuevo Solistahuacán \\
\hline 32 & B. occidentalis & Mexico: Chiapas & Julian Grijales, W of Pueblo Nuevo Solistahuacán \\
\hline 33 & B. occidentalis & Mexico: Chiapas & W of Rayon \\
\hline 34 & B. occidentalis & Mexico: Chiapas & SE of Puerto Cate \\
\hline 35 & B. occidentalis & Mexico: Chiapas & Finca Prusia \\
\hline 36 & B. occidentalis & Mexico: Chiapas & 14 km N Tapachula on road to Finca Nueva Alemania \\
\hline 37 & B. occidentalis & Mexico: Chiapas & 7.5 km N Cacahoatán \\
\hline 38 & B. occidentalis & Guatemala: San Marcos & Finca Santa Julia \\
\hline 39 & B. occidentalis & Guatemala: San Marcos & 2 km S San Rafael Pie de la Cuesta \\
\hline 40 & B. nympha & Guatemala: Huehuetenango & Chancolín \\
\hline 41 & B. nympha & Guatemala: Baja Verapaz & Finca Sabó, Purulhá \\
\hline 42 & B. nympha & Guatemala: Alta Verapaz & Finca el Volcán, Senahú \\
\hline 43 & B. nympha & Belize: Toledo & Blue Creek National Park \\
\hline 44 & B. nympha & Guatemala: Izabal & Cerro Sarstún, Lívingston \\
\hline 45 & B. nympha & Guatemala: Izabal & Las Escobas, Cerro San Gil \\
\hline 46 & B. nympha & Guatemala: Zacapa & Finca la Bendición, Pinalito \\
\hline 47 & B. nympha & Guatemala: Zacapa & Finca las Granadillas, Pinalito \\
\hline
\end{tabular}


Table 1 Populations of Bolitoglossa (Nanotriton) used in phylogenetic analyses (Continued)

\begin{tabular}{llll}
\hline 48 & B. nympha & Guatemala: Zacapa & 5.2 km SE La Unión \\
\hline 49 & B. nympha & Honduras: Copan & El Limón, Sierra del Espíritu Santo \\
\hline 50 & B. nympha & Honduras: Copan & Santa Rosa de Copan \\
\hline 51 & B. nympha & Guatemala: Izabal & Finca la Firmeza, Sierra Caral \\
\hline 52 & B. nympha & Honduras: Santa Barbara & Montaña de Joconales \\
\hline 54 & B. nympha & Honduras: Cortés & Santa Teresita \\
\hline 55 & B. nympha & Honduras: Cortés & Aldea Buenos Aires \\
\hline 56 & B. nympha & Honduras: Cortés & Sierra del Espíritu Santo, W San Pedro Sula \\
\hline 57 & B. nympha & Honduras: Cortés & 11 km W of CA-5 at Hospital Cemesa, San Pedro Sula \\
\hline
\end{tabular}

for $16 S$ between localities 39 and 28, 0.10 for $c y t b$ between localities 22 and 37); GTR distances between individuals from all localities for each gene are given in Additional files 1, 2, 3: Tables S2, S3, S4. Our samples from the Sierra de los Chimalapas (locality 22; Figure 1) are from near the type locality of Bolitoglossa bilineata [33], synonymized with B. occidentalis by Wake and Brame [34]. Locality 22 is nested within $B$. occidentalis in our mtDNA gene tree.

Bolitoglossa rufescens comprises several well-supported, divergent lineages. Two groups of populations from the Los Tuxtlas region form a basal polytomy with all remaining populations. Samples from either side of the Isthmus of Tehuantepec are not reciprocally monophyletic; those from the eastern end of the TMVB in Veracruz and northern highlands of Oaxaca are in a clade with samples from Chiapas and the Sierra de los Chimalapas (Figure 2). Yet another clade of B. rufescens consists of samples from northwestern Guatemala.

Although $B$. nympha was described only from the type locality (locality 50) in Guatemala [35], Rovito et al. [27] hypothesized that populations from eastern Guatemala and western Honduras could be assigned to this species based on morphological data as well as allozyme results from Larson [29]. Campbell et al. [35] also stated that a specimen from Belize might be assignable to B. nympha based on a published $c y t b$ sequence. The mtDNA gene tree shows a deep divergence between populations formerly assigned to B. rufescens from Mexico and northwestern Guatemala and those from eastern Guatemala, Belize, and Honduras (Figures 1, 2). Given that the latter group of populations includes the type locality of B. nympha, we assign all these populations to that species, which is now known from a much broader geographic area than in the original description.

Results from phylogenetic analyses of the $P O M C$ data (Figure 3) mirror those from mtDNA in most respects. Bolitoglossa occidentalis and B. chinanteca are again placed in a clade that is the sister lineage of the other two species of Nanotriton, and B. chinanteca is monophyletic. The sample from nearest the type locality of
B. bilineata is again nested within a group of other samples of $B$. occidentalis from Chiapas, in agreement with the mtDNA results, providing no support for the distinctiveness of this named taxon. The single sample of $B$. hartwegi included in the dataset fell within this clade, rather than outside Nanotriton; this relationship is strongly supported $(\mathrm{BS}=88, \mathrm{PP}=0.99)$, suggesting that the relationship between the subgenera Nanotriton and Mayamandra should be further investigated using additional markers. Both B. rufescens and B. nympha are supported as monophyletic. Within $B$. rufescens, the initial divergence is once again resolved to be between populations from Los Tuxtlas and all other populations (Figure 3), and samples on either side of the Isthmus of Tehuantepec are not reciprocally monophyletic. A haplotype network constructed using the program TCS with the POMC data shows four separate networks and similar patterns to the phylogenetic tree results (Figure 4). The first corresponds to B. nympha and B. rufescens, which are separated by 8 mutational steps. The second network consists of samples of B. occidentalis and B. chinanteca, which are separated by 7 mutational steps, and the final two networks correspond to samples of $B$. hartwegi and B. mexicana (the outgroup in phylogenetic analyses). Bolitoglossa rufescens and B. occidentalis show both a higher diversity of haplotypes and more divergence between haplotypes compared to $B$. nympha. There was no discordance between the mitochondrial and POMC gene trees in terms of individuals being placed within clades corresponding to species; all samples from near contact zones fall into a clade corresponding to the same species in both the mtDNA and POMC gene trees. No individual has $P O M C$ haplotypes belonging to two different species, as we would expect if our dataset contained interspecific hybrids.

We are reluctant to undertake a molecular dating analysis of all divergences in the group due to a lack of appropriate fossil calibration points. Despite this, we estimated a chronogram with mtDNA data from all 


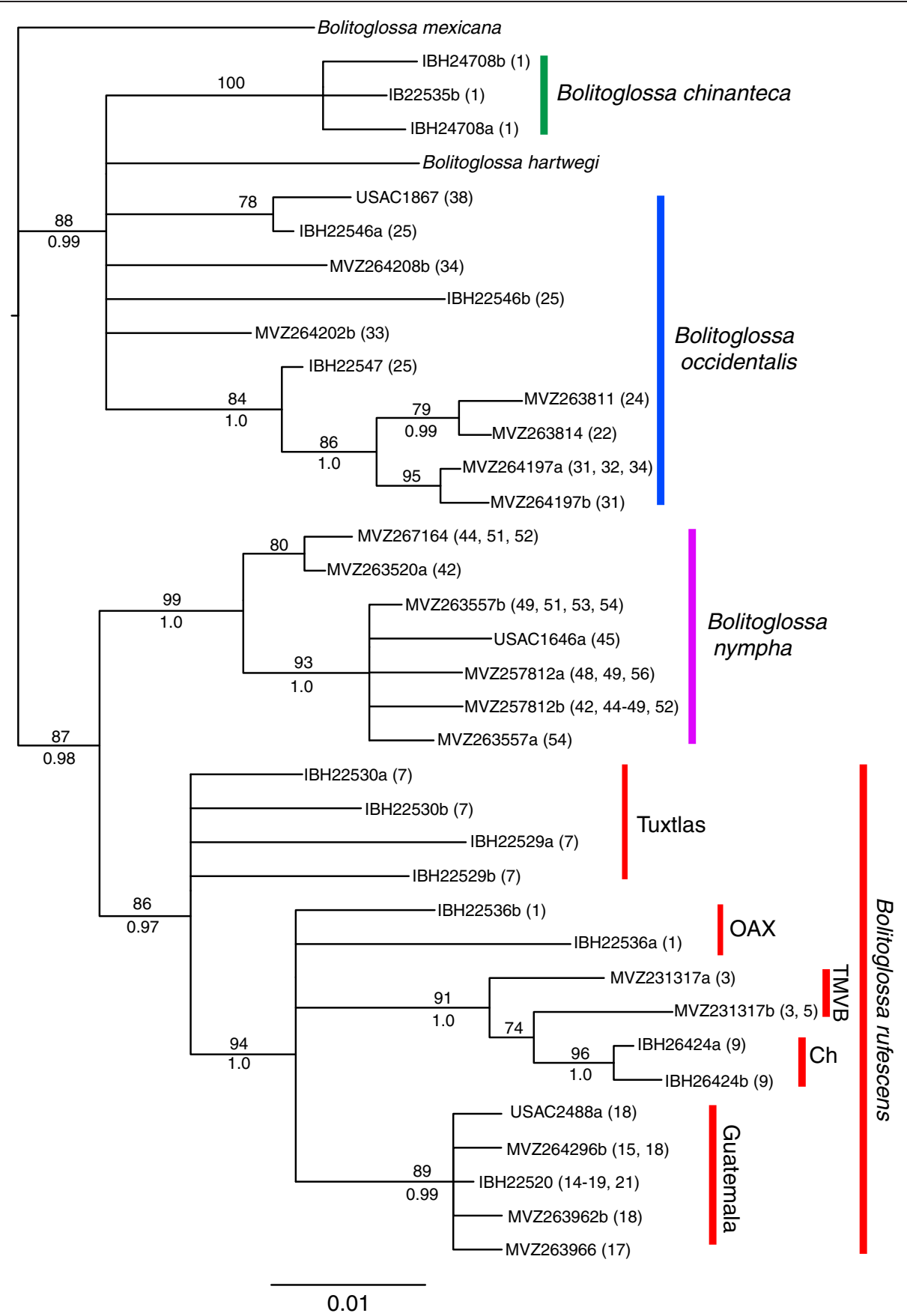

Figure 3 Results of RAxML analysis of POMC sequences. Haplotypes from heterozygous individuals are designated by a and b following the voucher number. Only one individual per haplotype is shown on the tree; thus, heterozygous individuals sharing haplotypes with other individuals do not appear. Numbers in parentheses after voucher numbers refer to all sampled localities (from Table 1) where haplotype was found. Bootstrap support values displayed above branches and posterior probabilities from Bayesian analysis below branches. Bootstrap values below 70 and posterior probabilities below 95 not shown. Geographic areas are shown for samples of Bolitoglossa rufescens. Abbreviations: Ch-Chiapas; TMVB-eastern terminus of Trans-Mexican Volcanic Belt; OAX-highlands of northern Oaxaca.

samples used in our phylogenetic analyses in order to calculate the divergence time of populations of B. rufescens that span the Isthmus of Tehuantepec. We used two different published substitution rate estimates for cytb from a fossil-calibrated phylogenetic analysis of plethodontids [36] and a rate that has been used as a general vertebrate molecular clock [37] in order to compare the timing of this divergence to that seen in other species. Populations of $B$. rufescens separated by the Isthmus of Tehuantepec were estimated to have diverged 3.3 
million years ago (Ma) using the slower substitution rate estimate in the BEAST analysis, or 1.9 Ma using the faster rate.

Results of analyses of phylogeographic structure and ancestral origin of clades from Phylomapper analyses indicate that significant phylogeographic structure is present within both Bolitoglossa occidentalis and $B$. rufescens. Both species show a significant association between phylogenetic and geographic distance, as measured by the scaled dispersal parameter $(\Psi)$, compared to the null expectation derived from randomizing the location of sampled individuals [32] (B. rufescens: mean $\Psi=177.66, \mathrm{p}<0.0001 ;$ B. occidentalis: $\Psi=33.84, \mathrm{p}<0.0001)$. The ancestral location of $B$. rufescens was reconstructed as being on the eastern side of the Isthmus of Tehuantepec (Figure 5), but is not significantly different from the null expectation of an origin at the center of its range $\left(\chi^{2}=1.69\right.$, $\mathrm{p}=0.43, \mathrm{df}=2$ ). Furthermore, likelihood ratio tests failed to reject an ancestral location of $B$. rufescens in either the northern highlands of Oaxaca $\left(\chi^{2}=4.79, \mathrm{p}=0.09, \mathrm{df}=2\right)$ or in Los Tuxtlas $\left(\chi^{2}=5.25, \mathrm{p}=0.07, \mathrm{df}=2\right)$. For $B$. occidentalis, the location of the ancestor was estimated to be on the eastern side of the Sierra Madre de Chiapas (Figure 5). The ML estimate of the location of the ancestor of B. occidentalis was significantly different from the center of the species' range $\left(\chi^{2}=6.20, \mathrm{p}=0.045, \mathrm{df}=2\right)$. Alternate locations for the ancestor of B. occidentalis in the Berriozabal area (localities 24), Sierra de los Chimalapas (locality 22), and the Pacific coast

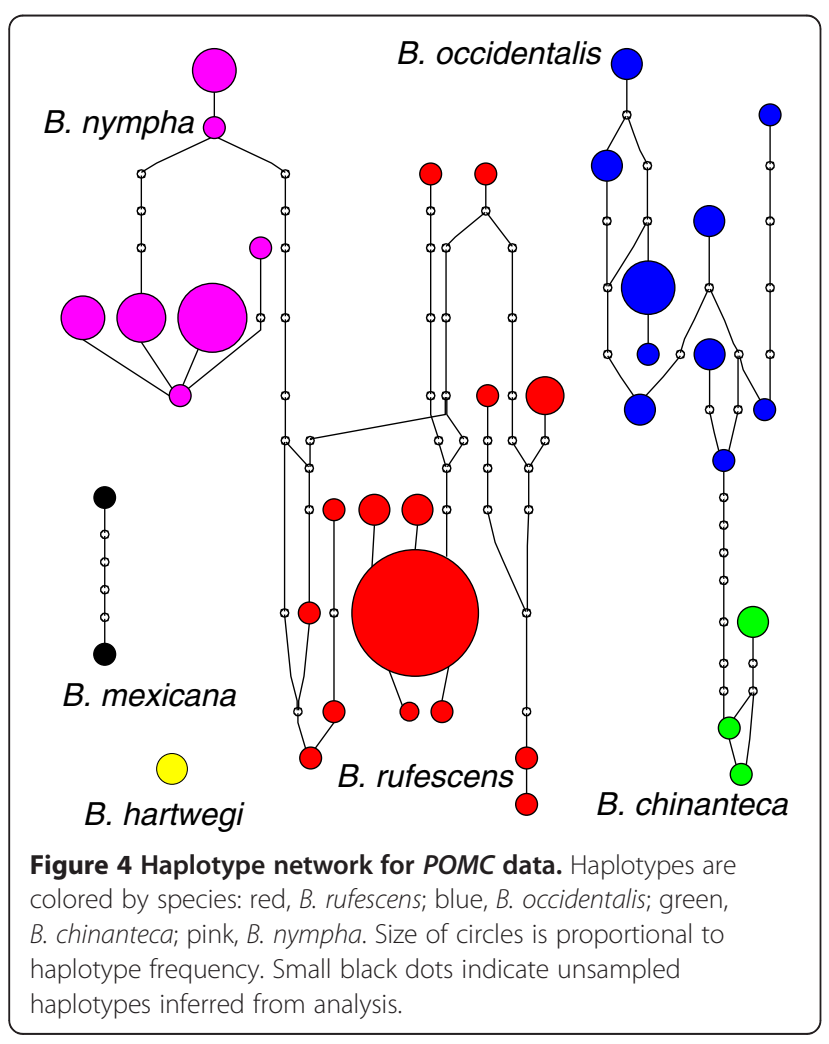

of southeastern Chiapas (locality 36) were all significantly less likely than the ML estimate (Berriozabal: $\chi^{2}=10.08$, $\mathrm{p}=0.0064$; los Chimalapas: $\chi^{2}=18.80, \mathrm{p}<0.0001$; Pacific coast: $\chi^{2}=44.02, \mathrm{p}<0.0001 ; \mathrm{df}=2$ for all tests).

For species with significant phylogeographic structure detected in Phylomapper, we performed analyses to determine the geographic location of genetic barriers using the program Barrier v2.2. These analyses identified the split between populations in Guatemala from all others in Mexico as the primary genetic barrier within B. rufescens. Two barriers separating the Los Tuxtlas populations from others in Mexico were then demarcated, followed by a fourth barrier across the Isthmus of Tehuantepec (Figure 6). Within $B$. occidentalis, the first barrier identified was between a group of populations on the Pacific coast of Guatemala/southeastern Chiapas and the Sierra Madre de Chiapas (Localities 35-39) and all other populations in Mexico. The second barrier delineated the populations in the Sierra de los Chimalapas (Locality 22) and a single locality from central Chiapas from others in central and northern Chiapas, and the third separated the single population in the Sierra Madre de Chiapas (Locality 35) from others in southeastern Chiapas and Guatemala.

A hierarchical Analysis of Molecular Variance (AMOVA) for Bolitoglossa rufescens was used to test for significant genetic structure at two levels: 1) among regional groups consisting of Los Tuxtlas, Nuclear Central America, and the TMVB/Oaxacan highlands, and 2) among populations from Chiapas and Guatemala within Nuclear Central America and from the TMVB and Oaxacan highlands within third group. The AMOVA showed significantly more genetic variance partitioned between populations within regional groups compared to the null expectation from permuting haplotypes among populations within groups (sum of squared deviations [SSD] among populations within groups $=81.50$, total $\mathrm{SSD}=266.68, \mathrm{DF}=2$. $\mathrm{p}<0.0001, \mathrm{DF}=2 . \mathrm{p}<0.0001$ ), but variance among regional groups was not larger than would be expected by chance (SSD among groups=125.18, total SSD = 266.68, $\mathrm{DF}=2$. $\mathrm{P}=0.60$ ). An AMOVA for B. occidentalis with four populations from the Sierra de los Chimalapas, northern and central Chiapas, the Sierra Madre de Chiapas, and the Pacific coast of southeastern Chiapas and Guatemala showed significantly more genetic variance partitioned among populations than expected by chance (SSD among populations= 97.419, total $\mathrm{SSD}=157.813, \mathrm{DF}=3, \mathrm{p}<0.0001)$.

\section{Discussion}

A high degree of phylogeographic structure characterizes both Bolitoglossa rufescens and B. occidentalis, as revealed both by the significant phylogeographic association test from Phylomapper and the presence of multiple divergent lineages present within both species. 


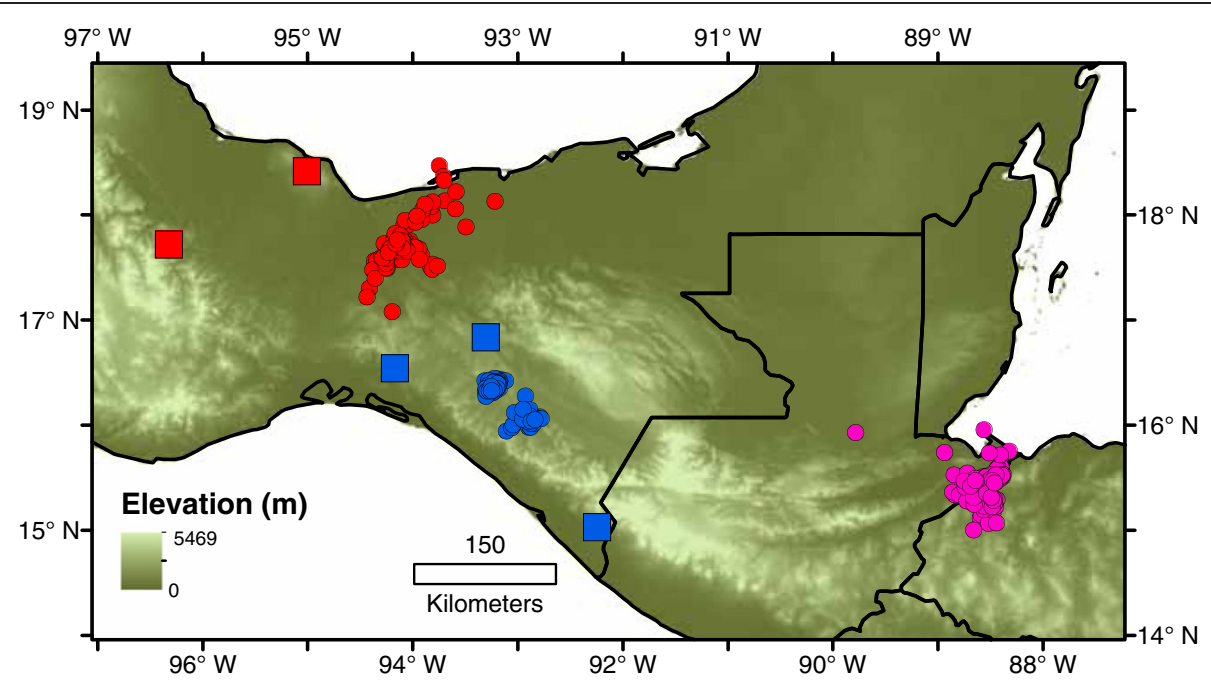

Figure 5 Results of Phylomapper analyses. Small circles indicate estimated location of ancestor of each clade from 100 replicate runs accounting for phylogenetic uncertainty in mtDNA gene tree. Squares indicate alternative ancestral locations used for hypothesis testing. Ancestral locations for $B$. nympha were not tested due to a lack of resolution in the mtDNA gene tree (see Methods). Red symbols: Bolitoglossa rufescens; blue symbols: B. occidentalis, pink symbols: $B$. nympha.

Bolitoglossa rufescens is known from a number of localities on both sides of the Isthmus of Tehuantepec and in the isolated Sierra de los Tuxtlas, making it one of only two species of salamander (along with B. platydactyla) to be distributed in all three of these areas. Although the Phylomapper results reconstruct a Central American origin for the species, an ancestral location within either the highlands of northern Oaxaca or in Los Tuxtlas could not be rejected. Indeed, the null hypothesis of an ancestral location at the center of the species' current range could also not be rejected. Our inability to distinguish between these hypotheses may be due to the fact that the three major areas where B. rufescens is found meet in approximately the center of its range, and its history appears to be relatively deep in both Los Tuxtlas and Nuclear Central America. Nucleotide diversity for $16 S$ is low in the TMVB/northern Oaxacan highlands $(\pi=0.0040 \pm 0.0037)$ compared to both los Tuxtlas $(\pi=0.014 \pm 0.011)$ and Central America $(\pi=0.021 \pm 0.012)$, which points to an origin for the species outside of the TMVB/northern Oaxacan highlands. The fact that initial divergences within $B$. rufescens are between Los Tuxtlas and all other areas in both the mtDNA and $P O M C$ gene trees suggests that this area may have been the origin of the species, or minimally that $B$. rufescens has been present in Los Tuxtlas for a long period of time. Volcanism that created the Sierra de los Tuxtlas began around $7 \mathrm{Ma}$, and several of the major volcanoes were formed sometime between from 3-1 Ma [38]. Although no calibration points are available for an accurate molecular dating analysis, the deep divergence between the samples from Los Tuxtlas and the clade from the TMVB/Oaxacan highlands and Nuclear Central America for both mtDNA and POMC most likely coincided with the early formation of the Tuxtlas volcanic complex.

Multiple species of amphibians show either disjunct distributions (Pseudoeurycea werleri [17], Pseudoeurycea nigromaculata [39], Anotheca spinosa [40]) or sister species pairs (Pseudoeurycea orchimelas and P. orchileucos [41]; Thorius pennatulus and T. narismagnus [16,39]) between the eastern terminus of the TMVB of Veracruz or highlands of northern Oaxaca and Los Tuxtlas, while other sister species pairs are found on either side of the Isthmus of Tehuantepec in Los Tuxtlas and the Sierra de los Chimalapas [42]. The only other lowland Bolitoglossa in the area, B. platydactyla, is present at low elevations in the Sierra Madre Oriental, eastern terminus of the TMVB, northern Oaxaca, Los Tuxtlas, and in northern Chiapas. Campbell (1984) proposed a closer relationship between the herpetofauna of Los Tuxtlas and the Chimalapas than between Los Tuxtlas and the northern Oaxacan highlands, and observed that the lowland area between los Tuxtlas and other highland areas of southern Mexico must have contained forest in the past to allow for interchange between these areas. The lowland areas around Los Tuxtlas today, which include both savannah and wetlands, do not contain any known populations of B. rufescens that would indicate a more continuous distribution in the recent past between these volcanoes and other areas where Nanotriton are found, although more searches would be needed to confirm this. The high nucleotide diversity of Los Tuxtlas compared to the TMVB/northern Oaxacan highlands and the high genetic distance between Los Tuxtlas and all other 


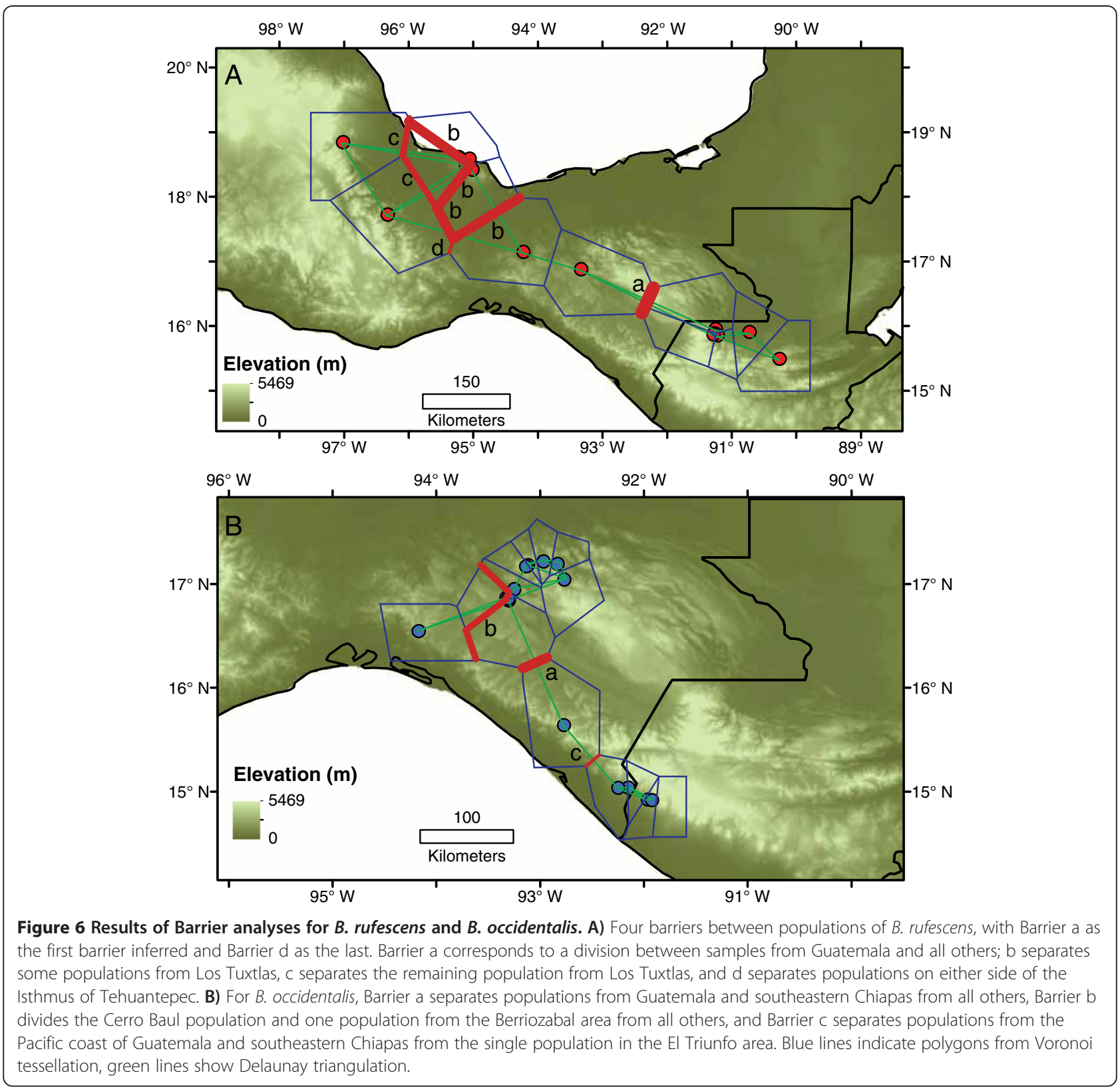

populations of B. rufescens follow the pattern of divergence and endemism seen in more highland amphibian and reptile species with similar distributions and indicate the Los Tuxtlas populations have been isolated from other highland areas of southern Mexico for a long time. Indeed, the B. rufescens from Los Tuxtlas are the only population of the species with maxillary teeth [29], a morphological character often used to delimit species of tropical salamanders $[16,43]$. The Los Tuxtlas populations may warrant description as an additional species endemic to the volcanic complex, and merit further study.

Mulcahy et al. [44] found that the Isthmus of Tehuantepec corresponded to a phylogeographic break in both Incilius valliceps and Rhinella marina, two lowland toads distributed widely in Mexico and Central America. They dated this divergence to approximately $2-3 \mathrm{Ma}$ in both species, and suggested that these data were consistent with the existence of a Pliocene seaway across the Isthmus that may have caused vicariance between populations on either side. Using divergence values recalculated separately for each gene, their data show levels of divergence across the Isthmus for both species that are higher those seen for $B$. rufescens for $16 \mathrm{~S}$ ( $R$. marina: mean $16 S$ GTR distance $=0.011$, $I$. valliceps: 0.0088 ) but lower for cytb ( $R$. marina: mean cytb GTR distance $=0.026$; I. valliceps $=0.020$ ); . . rufescens populations from the TMVB/northern Oaxacan highlands and those from Chiapas in Nuclear Central America have mean 
pairwise GTR distances of 0.0062 for $16 S$ and 0.040 for $c y t b$. The fact that the trans-Isthmus divergence values for $B$. rufescens are not consistently higher or lower suggests that $B$. rufescens may have been affected by this barrier in a similar manner as the toads. Although substitution rate estimates for this group of tropical salamanders are not available, using two substitution rates for cytb from the literature gives a divergence estimate of 1.9 or $3.2 \mathrm{Ma}$, roughly concordant with the timing of the Pliocene seaway; the second estimate uses a rate derived from a phylogenetic analysis of plethodontids [36], and may represent a better estimate of the divergence time. Samples of B. rufescens from north and south of the Isthmus are not reciprocally monophyletic for mtDNA; samples from the TMVB/northern Oaxacan highlands render those from Central American paraphyletic. This suggests that any phylogeographic structure caused by the breaks in forested habitat associated with formation of the Isthmus or by formation of a seaway across the Isthmus postdates earlier phylogeographic structure associated with geologic or climatic barriers within Central America. The fact that genetic structure within $B$. rufescens associated with the Isthmus is relatively shallow compared to that within Nuclear Central America is reflected in the Barrier analysis results, which showed that the Isthmus corresponds to the fourth most important barrier within the species, after barriers within Nuclear Central America and Los Tuxtlas. Similarly, the AMOVA results show that while significant genetic structure is present among populations within regions, genetic structure is not significant at the regional level, indicating that divisions between regions such as the Isthmus do not correspond to locations of the primary genetic divisions between the species.

In addition to its possible role as a barrier between the Oaxacan highlands and Central America, the Isthmus may have isolated populations in Los Tuxtlas from those in Central America. The much deeper divergence seen between Los Tuxtlas and all populations in Central America may have been partly driven or reinforced by the formation of the Isthmus in the late Miocene or early Pliocene [45]. At an even deeper timescale, Bolitoglossa occidentalis and B. chinanteca were found to be sister taxa and are separated by the Isthmus of Tehuantepec. Based on our rate calibrations, their divergence is much too old to have been caused by a Pliocene seaway and likely predates the event. Given this difference in timing of the divergence between the two species and the formation of the Isthmus, the fact that their ranges are currently separated by the Isthmus suggests that caution must be used when inferring a causal role for geographic barriers based solely on overlap with genetic breaks.

Despite its small range and its distribution entirely within the Mayan geological block [46] of Nuclear Central America, B. occidentalis displays a high level of genetic diversity for both mtDNA and POMC. The Phylomapper results show significant phylogeographic structure within the species and reject an origin in any of the three main clusters of populations within our sampling or from the center of its current distribution. These results provide strong support for an origin of B. occidentalis on the eastern side of the Sierra Madre de Chiapas, near one of our sampled populations (Locality 35). While increased sampling of populations on both sides of the Sierra Madre de Chiapas could potentially change this result, our analyses indicate that $B$. occidentalis arose in an area of Caribbean drainage. Bolitoglossa rufescens is entirely confined to Caribbean-draining areas of Mexico and Central America, while B. occidentalis is primarily found on the Pacific side of Central America [15] (Figure 1). If both species arose within the Caribbean drainage, some other factor besides isolation across the Caribbean-Pacific divide must have been responsible for their initial divergence. The Barrier results show that the primary division within the species is between populations in southeastern Chiapas and Guatemala and all others, and the AMOVA results also show significant structure between the different areas where B. occidentalis is found.

The limited divergence between populations and lack of strong phylogeographic structure within Bolitoglossa nympha stands in contrast to that seen in both $B$. rufescens and B. occidentalis. Bolitoglossa nympha ranges across a major geographic barrier, the Motagua-Polochic fault system [21,22], yet this fault and associated subhumid areas seem not to have caused vicariance or population isolation within B. nympha. Bolitoglossa nympha and B. rufescens may have been separated by the Motagua-Polochic fault in the past, with a subsequent expansion of $B$. nympha to the northwest of the fault, bringing the two species into secondary contact. Likewise, areas where the distributions of B. nympha and B. rufescens approach each other in both the Sierra de los Cuchumatanes (localities 14-18 and 40, Figure 1C) and the Sierra de Xucaneb (localities 21 and 41-42; Figure 1D) in Guatemala present no obvious geological or climatic barrier that could have either caused the divergence between the two species or maintained them in allopatry. The low haplotype diversity and lack of strong phylogeographic structure within $B$. nympha suggest that the species may have undergone a historical bottleneck or reduction in range. Modeling of the extent of wet forest habitat, with which species of Nanotriton are generally associated, in Central America at the Last Glacial Maximum predicted an absence of this habitat in northeastern Honduras and eastern Guatemala [47], covering most of the current range of B. nympha. While this area was previously hypothesized as a Pleistocene refugium for plant taxa [48], the absence of humid forest over most of the range of $B$. nympha east of the Motagua fault during the Pleistocene could 
explain both the lack of strong phylogeographic structure within the species compared to B. rufescens and B. occidentalis and the lack of a phylogeographic break across the Motagua-Polochic fault.

\section{Conclusions}

Species of Nanotriton have a long history in Central America. The deepest divergences within and between species of Nanotriton do not appear to have been caused by restricted dispersal across biogeographic barriers identified for other taxa, such as the Isthmus of Tehuantepec and Motagua-Polochic fault system. While the Isthmus of Tehuantepec did cause vicariance of populations of Bolitoglossa rufescens, this divergence is shallow compared to others within both $B$. rufescens and B. occidentalis. The distinctiveness of $B$. rufescens from Los Tuxtlas appears to be the exception to this pattern, and reinforces the importance of Los Tuxtlas as a site of high endemism and biogeographic distinctiveness within southeastern Mexico. Aside from Los Tuxtlas, the highest intrapopulation divergence within both $B$. occidentalis and $B$. rufescens has taken place within the Mayan block of Nuclear Central America. This relatively strong phylogeographic structure over small spatial scales could result in the formation of separate species over longer timescales. The external morphological similarity of all species in the subgenus has hidden the high phylogeographic structure present within two of these species, and subsequent morphological examination of populations from Los Tuxtlas or B. occidentalis from Chiapas could show that additional independent lineages warrant recognition as distinct species. Despite their morphological similarity, we found no evidence of introgression at or near contact zones. Differences in levels of phylogeographic structure between $B$. rufescens and $B$. nympha may be related to regional differences in historical forest extent, which is hypothesized to have varied over time [47,48]. This phenomenon should be tested by examining patterns of genetic variation within other forest-inhabiting taxa with similar distributions to these two salamander species. The phylogeographic history of Nanotriton serves as a useful comparison to both higher elevation forest taxa $[21,22,49]$ and lowland, arid-adapted species [24], and provides an important addition to our understanding of factors responsible for population divergence and speciation across a geologically complex landscape.

\section{Methods}

\section{Study system and sample collection}

Populations of all four species of Nanotriton were sampled throughout Mexico, Guatemala and Honduras during fieldwork from 2005 to 2011, as well as from the Museum of Vertebrate Zoology tissue collection. Populations of B. rufescens in eastern Guatemala and Honduras belong to a second, recently described species, $B$. nympha [35]; this species was described only from the type locality, but other populations from the region bear a morphological resemblance to the type series [27,29]. Bolitoglossa occidentalis occurs from extreme eastern Oaxaca to the Pacific coast of Guatemala; we examined a single individual reported to B. occidentalis from the Caribbean side of Honduras [50], and determined it to be a juvenile of another subgenus (most likely subgenus Bolitoglossa). When this record is excluded, nearly all portions of the known range of these species were sampled in our study. Permits for specimen collection and export were provided to GPO in Mexico by SEMARNAT, to CRVA in Guatemala by CONAP, and to SMR in Honduras by COHDEFOR.

We collected a total of 96 individuals from 57 localities (Additional file 4: Table S1, Figure 1). Most individuals were found by searching in the outer layers of the trunks of banana plants in plantations or coffee groves, but some were found in arboreal bromeliads, under cover objects, or at night on vegetation. Liver and/or tail tissue was collected and stored either in ethanol, liquid nitrogen, or RNALater buffer in the field, and subsequently transferred to $-80^{\circ} \mathrm{C}$. Voucher specimens were deposited in the Museum of Vertebrate Zoology (MVZ) at the University of California, Berkeley, the Instituto de Biología, Universidad Nacional Autónoma de México (IBH), or the Museo de Historia Natural, Universidad de San Carlos, Guatemala (USAC).

\section{Sequencing and phylogenetic analysis}

We extracted DNA from liver or tail tissue using either DNeasy extraction kits (Qiagen, Valencia, CA, USA) or a guanidine thiocyanate extraction protocol. The guanidine thiocyanate protocol involves cell lysis at $55^{\circ} \mathrm{C}$ for $3-12$ hours, protein precipitation using guanidine thiocyanate followed by centrifugation for $10 \mathrm{~min}$, and DNA precipitation using $100 \%$ isopropanol followed by centrifugation for $10 \mathrm{~min}$. We sequenced two mitochondrial genes, the large subunit ribosomal RNA gene (16S) using primers $16 \mathrm{Sar}$ and $16 \mathrm{Sb}$ [51] and cytochrome $b$ (cytb) using primers MVZ15 and MVZ16 [52], as well as one nuclear gene, proopiomelanocortin (POMC) using primers POMC_DRV_F1 and POMC_DRV_R1 [53]. PCR amplification consisted of an initial denaturation step at $95^{\circ} \mathrm{C}$ for $2 \mathrm{~min}$, followed by 38 cycles of denaturation at $95^{\circ} \mathrm{C}$ for $30 \mathrm{~s}$, annealing at $48^{\circ} \mathrm{C}(16 \mathrm{~S}$ and $c y t b)$ or $57^{\circ} \mathrm{C}$ $(P O M C)$ for $1 \mathrm{~min}$, and extension at $72^{\circ} \mathrm{C}$ for $1 \mathrm{~min}$, with a final extension at $72^{\circ} \mathrm{C}$ for $7 \mathrm{~min}$. PCR products were purified using 1uL of EXOSAP-IT (USB Corp., Cleveland, OH, USA), cycle sequenced with BigDye3.1 terminator sequencing (Applied Biosystems, Foster City, CA, USA), purified using ethanol precipitation and run on an ABI-3730 capillary sequencer (Applied Biosystems, Foster City, CA, USA). Sequences were edited using Sequencher 
(GeneCodes, Ann Arbor, MI, USA) or Geneious v 5.1.7 [54] GenBank accession numbers for all sequences are given in Additional file 4: Table S1.

Sequences were aligned with Muscle v3.6 [55] using default parameters. Alignment lengths were 522 base pairs (bp) for $16 S, 772 \mathrm{bp}$ for $c y t b$, and $481 \mathrm{bp}$ for POMC. Gametic phase of POMC sequences was determined computationally using PHASE [56], and haplotype determinations from the best pairs output were used. When an individual had two distinct haplotypes for $P O M C$, both were used in gene tree reconstruction. We constructed gene trees separately for concatenated mitochondrial genes $(16 S+c y t b)$ and POMC using both maximum likelihood (ML) and Bayesian analyses, and removed redundant haplotypes prior to phylogenetic analysis. For ML analyses, the program RAxML v7.0.4 [57] was used. Mitochondrial data were partitioned by gene, and $c y t b$ data were further partitioned by codon position. A GTR+G+I substitution model was used for all ML analyses, and 1000 bootstrap replicates were run to assess nodal support; models less complex than the GTR model are not implemented in RAxML. We estimated gene trees using MrBayes 3.1.2 [58], with two runs and four chains (one cold, three heated) per run. MCMC analyses were run for $2^{*} 10^{7}$ generations, sampled every 1000 generations, and the first 5000 samples were discarded as burn-in. Rate variation across partitions was permitted, and default priors were used for other parameters. We used the sliding window and compare plots in the program AWTY [59] to check for convergence in Bayesian analyses. A sequence of Bolitoglossa (Bolitoglossa) mexicana was used as the outgroup for all phylogenetic analysis, and a sequence of Bolitoglossa (Mayamandra) hartwegi was also included in the dataset, given that the subgenera Bolitoglossa and Mayamandra were found to be the closest relatives of Nanotriton in previous analyses of mtDNA [20]. Sequence alignments and Bayesian consensus trees are archived in TreeBase (Submission 13756; http:// purl.org/phylo/treebase/phylows/study/TB2: S13756).

For Bayesian analyses, we tested several partitioning strategies for the mtDNA dataset: 1) all data as a single partition, 2) $16 S$ and $c y t b$ as separate partitions (two partitions), and 3) $16 S$ as one partition with $c y t b$ further partitioned by codon position (four partitions). For $P O M C$, we compared results with all data as single partition and with each codon position as a separate partition. The program MrModeltest [60] was used to determine the most appropriate model of nucleotide substitution for each partition using the AIC. We determined the most appropriate partitioning strategy for each locus using Bayes factors [61]. Comparison of results of Bayesian analyses with different partitioning strategies supported the 4-partition strategy for mtDNA (2ln (Bayes factor) 4 vs. 2 partitions-466; 4 vs. 1 partition-624; 2 vs. 1 partition-158) and 3 partitions for the POMC data
(2ln(Bayes factor) 3 vs. 1 partition-15). The following substitution models were used in the favored partitioning strategy: $16 \mathrm{~S},-\mathrm{GTR}+\mathrm{I}+\mathrm{G}$; $c y t b$ codon positon $1,2-\mathrm{HKY}+\mathrm{G}$; cytb codon position 3, POMC codon position $3-\mathrm{GTR}+\mathrm{G}$; POMC codon position 1 - F81; POMC codon position $2-\mathrm{HKY}+\mathrm{I}$. A haplotype network for the POMC data was constructed using TCS v 1.2.1 [62].

\section{Detection of interspecific hybridization}

No examples of hybridization are currently known for the subgenus Nanotriton, and these phylogeographic data are suitable for assessing whether these morphologically similar species come into contact and hybridize. In order to detect possible interspecific hybrids, larger numbers of salamanders were sequenced for zones where different species may contact each other in Chiapas, Mexico and Guatemala. Although B. chinanteca and $B$. rufescens are known to occur syntopically in Oaxaca, Mexico [27], only a few samples from this locality were available. In the area of Berriozabal, Chiapas, Mexico (localities 13, 23-25; Figure 1) and Chancolín, Guatemala (localities 14-18, 40; Figure 1), multiple individuals per locality were included in both $16 S$ and $P O M C$ phylogenetic analyses. Not all these individuals were sequenced for $c y t b$, since both mitochondrial genes are inherited as a single unit. If F1 hybrids were included in the sample, we would expect to see some individuals with distinct POMC haplotypes from two different species, given the degree of structure in the POMC gene tree (see Results). Additionally, for both F1 hybrids and some backcrosses, we would expect to see individuals with $16 S$ haplotypes from one species and $P O M C$ haplotypes from a different species.

\section{Phylogeographic analyses}

In order to determine the geographic origin of the three species with larger distributions (all except B. chinanteca), we used Phylomapper v1 [32]. This program uses geographic coordinates of collection localities of samples included in a phylogeny, along with branch length information, to estimate the geographic location of the ancestor of a clade using a random walk model of migration. Because branches of zero length produce infinite dispersal distance estimates (Phylomapper manual), the number of identical haplotypes was first reduced by sampling only a single individual from each site or cluster of sites. Mitochondrial sequences (either $16 S$ and $c y t b$ or $16 S$ alone) were used to construct a mtDNA gene tree using MrBayes from this sample set, with the same analysis parameters as in the analysis of all mtDNA sequences. To deal with remaining redundant haplotypes, one tree from the 15,000 fully resolved trees sampled from the posterior distribution by MrBayes was selected for each run using the "random" option in Phylomapper. The geographic origin of each species was calculated separately, using 100 runs of Phylomapper. For 
each analysis, rate smoothing was conducted for the clade of interest (the species whose geographic origin was being estimated), rather than for the entire Nanotriton clade.

Phylomapper was also used to test statistically for phylogeographic association, or a correlation between geographic distance and genetic distance, within a clade and for a difference between the estimated location of the ancestor of a clade and the geographic center of that clade. The Bayesian consensus tree was used for all hypothesis testing, rather than choosing a tree randomly from the posterior distribution, in order to conduct all tests on the same gene tree. Polytomies in the consensus tree were resolved arbitrarily by inserting branches of very short length $(0.0001)$. Statistical testing was not done for $B$. nympha because resolving the large number of polytomies between closely related haplotypes significantly changed the likelihood compared to runs using randomly chosen trees from the posterior distribution. For the phylogeographic association test, geographic coordinates from sampling localities were assigned randomly across tips and 10000 iterations were used to construct a null distribution of the scaled dispersal parameter $(\Psi)$. Several additional hypotheses related to the ancestral location of clades were also tested by fixing the location of the ancestor of the clade, optimizing the other parameters in the model and comparing the likelihood of the constrained model (location fixed) with the model with the ancestral location unconstrained using a likelihood ratio test with two degrees of freedom [32]. Within each region tested as an alternative ancestral location, the geographically closest population in our dataset to the estimated origin of the clade was used as the point locality for the alternative origin location. Bolitoglossa rufescens was tested for an origin in the northern Oaxacan highlands (locality 1), and for an origin in the Los Tuxtlas region of Veracruz (locality 8). Bolitoglossa occidentalis is confined to the Nuclear Central America region, but is distributed primarily in three areas within the region, and was tested for an ancestral location in each: northcentral Chiapas (locality 24), the Pacific coast (locality 36), and the Sierra de los Chimalapas (locality 22).

For species with a significant result from the Phylomapper phylogeographic association test, we used the program Barrier v2.2 [63] to infer the geographic location of barriers between samples with Monmonier's (1973) maximum difference algorithm [64]. Barrier identifies the spatial location of genetic breaks by dividing up geographic space using a Voronoi tessellation, creating a network of polygons each edge of which is equidistant to two sampling localities, and the centroids of these polygons (sample localities) are connected in a Delaunay triangluation, Monmonier's algorithm finds the edge of the triangulation with the maximum genetic distance, and traces a barrier along the edge of the Voronoi polygon perpendicular to this edge. It proceeds along adjacent edges until the edge of the triangulation or a previously defined barrier is reached [63]. We used PAUP [65] to calculate GTR distances between samples used in the Phylomapper analyses, and ran the analysis with four barriers for B. rufescens and three for B. occidentalis (which has a smaller geographic range). Larger numbers of barriers were tested, but began to finely subdivide geographically proximate populations.

We used Arlequin v3.5 [66] to calculate nucleotide diversity for clades within species with the Tamura-Nei (TN) [67] substitution model (the most parameterized model implemented in Arlequin) with a gamma correction, in order to compare levels of genetic diversity within subregions. We used the same mtDNA dataset in Phylomapper in order to remove multiple redundant haplotypes from sites near contact zones. The value of gamma from the substitution model chosen by MrModeltest 2.2 was used for distance calculation. For Bolitoglossa rufescens, samples were grouped into those from the eastern terminus of the TMVB/northern highlands of Oaxaca, Mexico (localities 1-5), Central America (localities 7-13), and those from Los Tuxtlas (localities 6-8), and the first two populations were used to compare divergence levels across the Isthmus of Tehuantepec. We also calculated nucleotide diversity for each species as a whole. Finally, we calculated mean GTR distances between species, as well as between geographic groups of populations within species of Nanotriton, using PAUP [65]. We also recalculated GTR distances across the Isthmus for two toad species (Rhinella marina and I. valliceps) from Mulcahy et al. [44], separating their $16 S$ and $c y t b$ data in order to allow comparison with our data. We also performed a hierarchical Analysis of Molecular Variance (AMOVA) [68] in Arlequin for $B$. rufescens and $B$. occidentalis, which showed significant phylogeographic structure in the Phylomapper analyses. Populations were divided into three regional groups for B. rufescens: Los Tuxtlas, Nuclear Central America, and the TMVB/Oaxaca Highlands, and the latter two groups were subdivided into populations from Chiapas, Guatemala, TMVB, and Oaxacan highlands. A hierarchical AMOVA was performed using $16 S$ sequences, with 1000 permutations used to assess significance. For B. occidentalis, an AMOVA with four groups was performed: the Sierra de los Chimalapas (locality 22), populations from northern and central Chiapas (localities 23-34), the population from the Sierra Madre de Chiapas (locality 35), and populations from the Pacific coast of southeastern Chiapas and Guatemala (localities 36-39).

\section{Divergence dating}

No fossil calibration points are available for tropical salamanders, complicating the use of molecular data to infer 
divergence dates. In order to gain a rough estimate of the divergence time between populations of $B$. rufescens on either side of the Isthmus of Tehuantepec, we used two different substitution rate estimates for $c y t b$ in a BEAST analysis [69] of the mtDNA data. The first rate of 0.0062 substitutions/site/Myr per lineage was estimated using a variety of fossil calibration points on a mitochondrial phylogeny of the Plethodontidae [36], while the second, faster rate of 0.01 substitutions/site/ Myr [37] has been used as a general vertebrate mtDNA clock. The BEAST analysis was done a separate GTR+G substitution model for gene. An uncorrelated lognormal relaxed clock model was used to estimate divergence dates. Analyses were run for $20 \times 10^{9}$ generations, sampled every 1000 generations, and Tracer v1.6 [70] was used to summarize posterior distributions of divergence times.

\section{Additional files}

Additional file 1: Table S2. General time reversible (GTR) distances between 165 haplotypes used in phylogenetic analyses.

Additional file 2: Table S3. General time reversible (GTR) distances between cytb haplotypes used in phylogenetic analyses.

Additional file 3: Table S4. General time reversible (GTR) distances between POMC haplotypes used in phylogenetic analyses.

Additional file 4: Table S1. Museum catalog numbers, locality information, geographic coordinates, and GenBank accession numbers for all tissues used in phylogenetic analyses.

\section{Competing interests}

The authors declare that they have no competing interests.

\section{Authors' contributions}

SMR helped design study, conducted fieldwork, carried out the molecular genetic studies, performed phylogenetic analyses, and drafted the manuscript. GPO and DBW helped design study, carried out fieldwork, and assisted with manuscript preparation. CRVA and RLR conducted fieldwork and assisted with manuscript preparation. All authors read and approved the final manuscript.

\section{Acknowledgements}

We thank T. Papenfuss, M. García-París, E. G. Ruano, and L. A. Muñoz-Alonso for help in the field, J. R. McCranie for providing tissues, and L. Márquez for help in the laboratory. Collecting permits were provided by CONAP (Guatemala), SEMARNAT (Mexico), and COHDEFOR (Honduras). S.M.R. was funded by a postdoctoral fellowship from UC MEXUS-CONACYT postdoctoral fellowship and a NSF Bioinventory grant (DEB 1026396). The project was partially funded by PAPIIT-UNAM IN212111 to G. P.-O.

\section{Author details}

'Museum of Vertebrate Zoology, 3101 Valley Life Sciences Building, University of California, Berkeley, CA 94720-3160, USA. 'Instituto de Biología, Universidad Nacional Autónoma de México, AP 70-153, Circuito Exterior, Ciudad Universitaria, CP 04310, México, D.F., México. ${ }^{3}$ Museo de Historia Natural, Escuela de Biología, Universidad de San Carlos, Calle Mariscal Cruz 1-56, Zona 10, Ciudad de Guatemala, Guatemala. ${ }^{4}$ Coordinación Técnica de Investigación, Secretaría de Medio Ambiente e Historia Natural, Av. de los Hombres llustres s/ n, Fraccionamiento Francisco I. Madero, Tuxtla Gutiérrez, CP 29000, Chiapas, México. ${ }^{5}$ Museum of Vertebrate Zoology and Department of Integrative Biology, 3101 Valley Life Sciences Building, University of California, Berkeley, CA 94720-3160, USA
Received: 13 September 2012 Accepted: 12 December 2012 Published: 29 December 2012

\section{References}

1. Fouquet A, Gilles A, Vences M, Marty C, Blanc M, Gemmell NJ: Underestimation of species richness in neotropical frogs revealed by mtDNA analyses. PLoS One 2007, 2:e1109.

2. Hanken J: Genetic variation in a dwarfed lineage, the Mexican salamander genus Thorius (Amphibia: Plethodontidae): taxonomic, ecological and evolutionary implications. Copeia 1983, 1983:1051-1073.

3. Bickford D, Lohman DJ, Sodhi NS, Ng PKL, Meier R, Winker K, Ingram KK, Das I: Cryptic species as a window on diversity and conservation. Trends Ecol Evol 2006, 22(3):148-155.

4. Avise JC, Arnold J, Ball RM, Bermingham E, Lamb T, Neigel JE, Reeb CA, Saunders NC: Intraspecific phylogeography: the mitochondrial DNA bridge between population genetics and systematics. Ann Rev Ecol Syst 1987, 18:489-522.

5. Avise JC, Walker D: Pleistocene phylogeographic effects on avian populations and the speciation process. Proc R Soc Lond B 1998, 265:457-463.

6. García-París M, Good DA, Parra-Olea G, Wake DB: Biodiversity of Costa Rican salamanders: Implications of high levels of genetic differentiation and phylogeographic structure for species formation. Proc Natl Acad Sci U S A 2000, 97:1640-1647.

7. Knowles LL: Tests of Pleistocene speciation in montane grasshoppers (genus Melanoplus) from the sky islands of Western North America. Evolution 2000, 54:1337-1348.

8. Barraclough TG, Vogler AP: Detecting the geographical pattern of speciation from species-level phylogenies. Am Nat 2000, 155:420-434

9. Schuchert C: Historical Geology of the Antillean-Caribbean Region. New York, NY: John Wiley and Sons; 1935.

10. Kozak KH, Blaine RA, Larson A: Gene lineages and eastern North American palaeodrainage basins: phylogeography and speciation in salamanders of the Eurycea bislineata species complex. Mol Ecol 2006, 15:191-207.

11. Martinez-Solano I, Jockusch EL, Wake DB: Extreme population subdivision throughout a continuous range: phylogeography of Batrachoseps attenuatus (Caudata: Plethodontidae) in western North America. Mol Ecol 2007, 16:4335-4355.

12. Crespi EJ, Rissler $L$, Browne RA: Testing Pleistocene refugia theory: phylogeographical analysis of Desmognathus wrighti, a high-elevation salamander in the southern Appalachians. Mol Ecol 2003, 12:969-984.

13. Hendrickson JR: Ecology and systematics of salamanders of the genus Batrachoseps. Univ Calif Publ Zool 1954, 54:1-46.

14. Spotila JR: Role of temperature and water in the ecology of lungless salamanders. Ecol Monogr 1972, 42:95-125.

15. Wake DB, Lynch JF: The distribution, ecology and evolutionary history of plethodontid salamanders in tropical America. Nat Hist Mus Los Angel Cty Sci Bull 1976, 25:1-65.

16. Hanken J, Wake DB: Biology of tiny animals: systematics of the minute salamanders (Thorius: Plethodontidae) from Veracruz and Puebla, Mexico, with descriptions of five new species. Copeia 1998, 1998:312-345.

17. Wake DB, Papenfuss TJ, Lynch JF: Distribution of salamanders along elevational transects in Mexico and Guatemala. Tulane Stud Zool Bot Suppl Publ 1992, 1:303-319.

18. Ghalambor CK, Huey RB, Martin PR, Tewksbury JJ, Wang G: Are mountain passes higher in the tropics? Janzen's hypothesis revisited. Integr Comp Biol 2006, 46:5-17.

19. Janzen DH: Why mountain passes are higher in the tropics. Am Nat 1967, 101:233-249.

20. Parra-Olea G, García-París M, Wake DB: Molecular diversification of salamanders of the tropical American genus Bolitoglossa (Caudata: Plethodontidae) and its evolutionary and biogeographical implications. Biol J Linn Soc 2004, 81:325-346.

21. Castoe TA, Daza JM, Smith EN, Sasa MM, Kuch U, Campbell JA, Chippindale PT, Parkinson CL: Comparative phylogeography of pitvipers suggests a consensus of ancient Middle American highland biogeography. J Biogeogr 2009, 36:88-103.

22. Daza JM, Castoe TA, Parkinson CL: Using regional comparative phylogeographic data from snake lineages to infer historical processes in Middle America. Ecography 2010, 33:343-354.

23. León-Paniagua L, Navarro-Sigüenza AG, Hernández-Baños BE, Morales JC Diversification of the arboreal mice of the genus Habromys 
(Rodentia: Cricetidae: Neotominae) in the Mesoamerican highlands. Mol Phylogenet Evol 2007, 42:653-664.

24. Devitt TJ: Phylogeography of the western lyresnake (Trimorphodon biscutatus): testing aridland biogeographical hypotheses across the Nearctic-Neotropical transition. Mol Ecol 2006, 15:4387-4407.

25. Duellman WE: A distributional study of the amphibians of the Isthmus of Tehuantepec, México. Univ Kans Publ Mus Nat Hist 1960, 13:19-72.

26. Muñoz-Alonso A, Lazcano-Barrero MA: Primer registro de Bolitoglossa platydactyla (Caudata: Plethodontidae) para Chiapas. Bol Soc Herpetol Mex 1992, 4:13-15.

27. Rovito SM, Parra-Olea G, Lee D, Wake DB: A new species of Bolitoglossa (Amphibia: Caudata) from the Sierra de Juárez, Oaxaca, Mexico. Zookeys 2012, 185:55-71

28. Poglayen I, Smith HM: Noteworthy herptiles from Mexico. Herpetologica 1958, 14:11-15.

29. Larson A: A molecular phylogenetic perspective on the origins of a lowland tropical salamander fauna 1. Phylogenetic inferences from protein comparisons. Herpetologica 1983, 39:85-99.

30. Alberch P: Convergence and parallelism in foot morphology in the Neotropical salamander genus Bolitoglossa. I. Function. Evolution 1981, 35:84-100.

31. Alberch P, Alberch J: Heterochronic mechanisms of morphological diversification and evolutionary change in the neotropical salamander, Bolitoglossa occidentalis (Amphibia: Plethodontidae). J Morphol 1981, 167:249-264.

32. Lemmon AR, Moriarity Lemmon E: A likelihood framework for estimating phylogeographic history on a continuous landscape. Syst Biol 2008, 57:544-561.

33. Lynch JD, Smith HM: New or unusual amphibians and reptiles from Oaxaca, Mexico, II. Trans Kans Acad Sci 1966, 69:58-75.

34. Wake DB, Brame AH: Systematics and evolution of neotropical salamanders of the Bolitoglossa helmrichi group. Contrib Sci (Los Angel Cty Mus) 1969, 175:1-40.

35. Campbell JA, Smith EN, Streicher J, Acevedo ME, Brodie ED Jr: New salamanders (Caudata: Plethodontidae) from Guatemala with miscellaneous notes on known species. Miscellaneous Publ Mus Zool Univ Mich 2010, 200:1-60.

36. Mueller RL: Evolutionary rates, divergence dates, and the performance of mitochondrial genes in Bayesian phylogenetic analysis. Syst Biol 2006, 56:542-542.

37. Brown WM, George M Jr, Wilson AC: Rapid evolution of animal mitochondrial DNA. Proc Natl Acad Sci U S A 1987, 76:1967-1971.

38. Nelson SA, Gonzalez-Caver E: Geology and K-Ar dating of the Tuxtla Volcanic Field, Veracruz, Mexico. Bull Volcanol 1992, 55:85-96.

39. Shannon FA, Werler JE: Notes on amphibians and reptiles from the Los Tuxtlas range of Veracruz, Mexico. Trans Kans Acad Sci 1955, 58:360-386.

40. AmphibiaWeb: Information on Amphibian Biology and Conservation. http://www.AmphibiaWeb.org. Accessed 1 December 2012.

41. Brodie ED Jr, Mendelson JR III, Campbell JA: Taxonomic revision of the Mexican plethodontid salamanders of the genus Lineatriton, with the description of two new species. Herpetologica 2002, 58:194-204.

42. Campbell JA: A new species of Abronia (Sauria: Anguidae) with comments on the herpetogeography of the highlands of southern Mexico. Herpetologica 1984, 40:373-381.

43. Hanken J, Wake DB: Five new species of Minute Salamanders, genus Thorius (Caudata: Plethodontidae), from northern Oaxaca, Mexico. Copeia 1994, 1994:573-590

44. Mulcahy DG, Morrill BH, Mendelson JR III: Historical biogeography of lowland species of toads (Bufo) across the Trans-Mexican Neovolcanic Belt and the Isthmus of Tehuantepec. Journal of Biogeography 2006, 33:1889-1904

45. Barrier E, Velasquillo L, Chavez M, Gualon R: Neotectonic evolution of the Isthmus of Tehuantepec (southeastern Mexico). Tectonophysics 1998, 287:77-96.

46. Marshall JS: The geomorphological and physiographic provinces of Central America. In Central America: Geology, Resources and Hazards, Volume Volume 2. Edited by Bundschuh J, Alvarado GE. Oxford, U.K: Taylor \& Francis; 2007:75-122.

47. Poelchau MF, Hamrick JL: Palaeodistribution modelling does not support disjunct Pleistocene refugia in several Central American plant taxa. J Biogeogr 2012, Online Early.
48. Brown KS: Areas where humid tropical forest probably persisted In Biogeography and Quaternary history in tropical America. Edited by Whitmore TC, Prance GT. Oxford, UK: Clarendon Press; 1987:44-45.

49. Bryson RW, Garcia-Vazquez UO, Riddle BR: Phylogeography of Middle American gophersnakes: mixed responses to biogeographical barriers across the Mexican Transition Zone. J Biogeogr 2011, 38:1570-1584.

50. McCranie JR, Wilson LD: The Amphibians of Honduras, Contributions to Herpetology, Volume 19. Ithica, NY: Society for the Study of Amphibans and Reptiles; 2002

51. Palumbi SR, Martin AP, Romano S, McMillan WO, Stice L, Grabowski G: The Simple Fool's Guide to PCR. Honolulu, Hawaii: University of Hawaii; 1991 Special Publication.

52. Moritz C, Schneider CJ, Wake DB: Evolutionary relationships within the Ensatina eschscholtzii complex confirm the ring species interpretation. Syst Biol 1992, 41:273-291.

53. Vieites DR, Min MS, Wake DB: Rapid diversification and dispersal during periods of global warming by plethodontid salamanders. Proc Natl Acad Sci U S A 2007, 104:19903-19907.

54. Geneious V. 5.1. Created by Biomatters. Available from http://www.geneious.com.

55. Edgar RC: MUSCLE: a multiple sequence alignment method with reduced time and space complexity. BMC Bioinformatics 2004, 5:1-19.

56. Stephens M, Smith NJ, Donnelly P: A new statistical method for haplotype reconstruction from population data. Am J Hum Genet 2001, 68:978-989.

57. Stamatakis A: RAxML-VI-HPC: Maximum likelihood-based phylogenetic analyses with thousands of taxa and mixed models. Bioinformatics 2006, 22:2688-2690.

58. Huelsenbeck JP, Ronquist F: MRBAYES: Bayesian inference of phylogenetic trees. Bioinformatics (Oxford) 2001, 17:754-755.

59. Nylander JAA, Wilgenbusch JC, Warren DL, Swofford DL: AWTY (are we there yet?): a system for graphical exploration of MCMC convergence in Bayesian phylogenetics. Bioinformatics 2008, 24:581-583.

60. Nylander JAA: MrModeltest. Program distributed by the author, version 2 Uppsala: Evolutionary Biology Centre, Uppsala University; 2004.

61. Brandley MC, Schmitz A, Reeder TW: Partitioned Bayesian analysis, partition choice, and the phylogenetic relationships of scincid lizards. Syst Biol 2005, 54:373-390.

62. Clement M, Posada D, Crandall KA: TCS: a computer program to estimate gene genealogies. Mol Ecol 2000, 9:1657-1659.

63. Manni F, Guérard E, Heyer E: Geographic patterns of (genetic, morphological, linguistic) variation: how barriers can be detected by using Monmonier's algorithm. Hum Biol 2004, 76:173-190.

64. Monmonier MS: Maximum-difference barriers: an alternative numerical regionalization method. Geogr Anal 1973, 5:245-261.

65. Swofford DL: PAUP*. Phylogenetic Analysis Using Parsimony ( ${ }^{*}$ and Other Methods), version 4.0. Sunderland, MA: Sinauer Associates; 2003.

66. Excoffier L, Laval G, Schneider S: Arlequin (version 3.0): An integrated software package for population genetics data analysis. Evol Bioinform Online 2005, 1:47-50.

67. Tamura K, Nei M: Estimation of the number of nucleotide substitutions in the control region of mitochondrial DNA in humans and chimpanzees. Mol Biol Evol 1993, 10:512-526.

68. Excoffier L, Smouse PE, Quattro J: Analysis of molecular variance inferred from metric distances among DNA haplotypes: application to human mitochondrial DNA restriction data. Genetics 1992, 131:479-491.

69. Drummond AJ, Rambaut A: BEAST: Bayesian evolutionary analysis by sampling trees. BMC Evol Biol 2007, 7:214.

70. Rambaut A, Drummond AJ: Tracer, Volume version 1.6.; 2007.

doi:10.1186/1471-2148-12-255

Cite this article as: Rovito et al:: Deep divergences and extensive phylogeographic structure in a clade of lowland tropical salamanders. BMC Evolutionary Biology 2012 12:255. 